\title{
Transient accumulations of cyanophycin in Amabaena cylindrica and Synechocystis 6308
}

\author{
Alison H. Mackerras, Nola M. De Chazal and Geoffrey D. Smith* \\ Department of Biochemistry, Faculty of Science, The Australian National University, GPO Box 4, Canberra, \\ ACT 2601, Australia
}

(Received 19 December 1989; revised 30 April 1990; accepted 6 July 1990)

\begin{abstract}
Cyanophycin, the nitrogen reserve compound in cyanobacteria, has a dynamic metabolism during transitions between the metabolic states of nitrogen deficiency and nitrogen repletion and vice versa. Cyanophycin was transiently synthesized when ammonia-grown Anabaena cylindrica or Synechocystis 6308 consumed a limited amount of ammonia. It was synthesized during the phase of declining ammonia concentration, and its degradation was complete by the time the external ammonia had been completely consumed. When nitrogen-starved cells of A. cylindrica or Synechocystis 6308 were given a usable source of fixed nitrogen, cyanophycin again accumulated transiently. This synthesis of cyanophycin was triggered by the suddenly renewed availability of fixed nitrogen, and not by the subsequent decline in the external concentration of fixed nitrogen. The cyanophycin was degraded when balanced exponential growth was again possible. Transient accumulations of cyanophycin with similar kinetics were also observed when ammonia was added to nitrogen-fixing $\boldsymbol{A}$. cylindrica. It is suggested that cyanophycin serves as a dynamic reservoir which separates the environmental supply of fixed nitrogen from the metabolic demands of the cells, and that this provides a mechanism which enables cyanobacteria to maximize their share of any available fixed nitrogen. This would give cyanobacteria a competitive advantage over other organisms.
\end{abstract}

\section{Introduction}

Micro-organisms in general, and cyanobacteria in particular, are noted for their ability to survive adverse conditions, including unpredictable shortages of essential nutrients. The survival strategy frequently involves the synthesis of an appropriate reserve compound, while the relevant nutrient is still available, and its use to support cell maintenance and growth when the nutrient supply has been exhausted (Dawes \& Senior, 1973; Allen, 1984; Simon, 1987). The mechanisms which regulate the observed synthesis and degradation of reserve compounds in cyanobacteria are still largely unknown.

Cohen and Parnas have considered the factors which control synthesis and degradation of reserve compounds in micro-organisms (Cohen \& Parnas, 1976; Parnas \& Cohen, 1976). In batch culture, cells are exposed to a continually falling concentration of available nutrient as the cells use the nutrient to support growth. When the substrate is exhausted, growth ceases and cells enter stationary phase, owing to exhaustion of that nutrient. Nutrient starvation thus follows a period of falling concentration. Parnas \& Cohen (1976) postulated that the falling concentration provides the signal for the coming period of starvation, and triggers synthesis of the appropriate reserve compound; its synthesis should thus occur during the transition to stationary phase.

Cyanophycin is a polypeptide consisting of aspartate and arginine residues, which is found only in cyanobacteria, where it serves as a nitrogen reserve. Cyanophycin usually accumulates during the stationary phase induced by a lack of a nutrient other than nitrogen, and disappears when balanced growth resumes (Allen, 1984; Simon, 1987). It also accumulates when nitrogen-starved or nitrogen-replete cells are given a usable nitrogen source (Allen \& Hutchison, 1980; Lawry \& Simon, 1982). In nitrogen-starved cells which were given a nitrogen source, cyanophycin accumulated transiently, and growth did not recommence until cyanophycin had been degraded again (Allen \& Hutchison, 1980). This demonstrates that cyanophycin has a dynamic metabolism under some conditions and is not simply metabolized during the exponential to stationary phase transition. Information about the accumulation of cyanophycin in nitrogen-replete cells is restricted to a single measurement made $48 \mathrm{~h}$ after the addition of nitrogen (Lawry \& Simon, 1982). The kinetics of cyanophycin synthesis under these conditions have not been studied. 
We have previously reported that cyanophycin was transiently synthesized and degraded when stationary phase nickel-depleted Anabaena cylindrica was used to inoculate fresh nickel-depleted medium (Daday et al., 1988). We have also observed an early transient accumulation of cyanophycin in analogous experiments with nickel-replete cells (unpublished observations), indicating that the presence of nickel influences the extent of the growth lag, but perhaps not the occurrence of a transient cyanophycin accumulation. The interpretation of these experiments was complicated by the presence of $0.18 \mathrm{~mm}$-ammonia in the growth medium (owing to the need to use Specpure chemicals for stringent nickel depletion; Daday et al., 1988), which would be consumed by the cells before induction of heterocysts and the transition to nitrogen-fixing metabolism. These questions are explored further in this communication. The transient accumulation of cyanophycin in $A$. cylindrica reported by Daday et al. (1988) was similar to that observed by Allen \& Hutchison (1980) in Synechocystis 6308. The BG-11 medium (Allen, 1968) used by the latter workers does not contain added nickel, and hence the possible influence of nickel on the observed cyanophycin peaks in that organism is also unknown.

The present work examines whether two distinct sets of conditions produce transient accumulations of cyanophycin, independently of any effect of nickel. These conditions are (1) those that prevail when a low concentration of external ammonia is consumed by the growing organism, and (2) those that involve the supply of fixed nitrogen to an organism following a period of nitrogen starvation.

\section{Methods}

Cyanobacterial growth. A. cylindrica (ATCC 27899) was grown as described in the accompanying paper (Mackerras et al., 1990). Cultures were routinely grown on $12 \mathrm{~h}$ light/12 h dark cycles and sparged with $0.3 \% \mathrm{CO}_{2}$ in air. When nickel-depleted cultures of $A$. cylindrica were required, they were prepared precisely as described by Daday $e t$ al. (1988). Synechocystis 6308 (PCC 6308) was obtained from the Pasteur Institute Culture Collection, Paris, France. It was grown in one-eighth strength Allen and Arnon medium (Allen \& Arnon, 1955) with full strength phosphate and additional $\mathrm{NiSO}_{4}(4 \times$ full-strength, $0.68 \mu \mathrm{M})$. The medium also included $10 \mathrm{~mm}-\mathrm{NaHCO}_{3}$ to maintain an appropriate $\mathrm{pH}$ during sparging with $0.3 \% \mathrm{CO}_{2}$ in air, and $2 \mathrm{~mm}-\left(\mathrm{NH}_{4}\right)_{2} \mathrm{HPO}_{4}$ to provide a nitrogen source. The cultures were incubated at $25^{\circ} \mathrm{C}$ at a light intensity of $120 \mu \mathrm{E} \mathrm{m}^{-2} \mathrm{~s}^{-1}$ and a $12 \mathrm{~h} \mathrm{light} / 12 \mathrm{~h}$ dark cycle. All experiments were started with cells that were not nitrogen-limited.

Assays. Growth was measured by light scattering (Klett units), dry weight and soluble protein as described in the accompanying paper (Mackerras et al., 1990). Cells were harvested by centrifugation, concentrated approximately 20 -fold, and suspended in $50 \mathrm{mM}$-Tricine/ $\mathrm{KOH}, 2 \mathrm{mM}-\mathrm{DTT}$, pH 8.2. Concentrated cells were frozen until cyanophycin extractions and other measurements could be done.
The isolation and measurement of cyanophycin have been described previously (Daday et al., 1988). Because lack of sufficient cell material was a continuing problem in the experiments, the reported cyanophycin concentrations are based on data obtained from single extractions at each time point. Phycocyanin was determined by $\boldsymbol{A}_{620}$ measurements on the supernatants obtained after thawed cells were broken by passage through the French Press (138 MPa) and centrifuged $(27000 \mathrm{~g}, 15 \mathrm{~min})$. Ammonia concentration in the medium was measured with the colorimetric assay described by Bergersen (1980) or with an Orion ammonia electrode as previously described (Daday et al., 1988).

Cyanophycin synthetase activity was measured according to the methods described by Simon (1976) and Gupta \& Carr (1981). Samples of cells were accumulated as described above and stored frozen until assay. Assays. were done on aliquots of centrifuged cell-free extracts, the same day as the extracts were made. The assay contained the following reagents in a total volume of $250 \mu \mathrm{l}$ : cell-free extract (up to $100 \mu \mathrm{l}),\left[{ }^{3} \mathrm{H}\right]$ arginine $\left[1 \mu \mathrm{Ci}(37 \mathrm{KBq})\right.$ in $10 \mu \mathrm{l}, \mathrm{L}-\left[5(\mathrm{n})-{ }^{-3} \mathrm{H}\right]$ arginine, Amersham], unlabelled arginine to give a total arginine concentration of $10 \mu \mathrm{M}$, aspartate $(100 \mu \mathrm{M})$, dithiothreitol $(2 \mathrm{mM})$, chloramphenicol $(34 \mu \mathrm{M}), \mathrm{KCl}(20 \mathrm{mM}), \mathrm{MgCl}_{2}(20 \mathrm{mM}), \mathrm{ATP}(4 \mathrm{mM})$ and cyanophycin (equivalent to $40 \mu \mathrm{g}$ arginine as measured by the colorimetric assay). Cyanophycin was dissolved in $0.01 \mathrm{M}-\mathrm{HCl}$, to allow the addition of reproducible amounts to the assays. The assay mixtures were incubated at $30^{\circ} \mathrm{C} ; 50 \mu \mathrm{l}$ samples were taken at 0,20 and $40 \mathrm{~min}$, and processed as described by Simon (1976).

Cyanophycinase activity was detected by measuring the $\left[{ }^{3} \mathrm{H}\right]$ arginine released from previously labelled cyanophycin. $\left[{ }^{3} \mathrm{H}\right]$ Cyanophycin was prepared by the method of Gupta \& Carr (1981). A. cylindrica cells incubated with $\left[{ }^{3} \mathrm{H}\right]$ arginine and chloramphenicol $\left(10 \mu \mathrm{g} \mathrm{ml}^{-1}\right)$ accumulated $\left[{ }^{3} \mathrm{H}\right]$ cyanophycin, which was isolated as previously described from cells broken by lysozyme and osmotic shock treatment (Schwinghamer, 1980). Cyanophycinase activity in cell-free extracts prepared in $50 \mathrm{mM}$-Tricine/KOH, $2 \mathrm{mM}$-DTT, pH 8.2 was measured by incubating $100 \mu \mathrm{g}$ cell protein at $30^{\circ} \mathrm{C}$, with $\left[{ }^{3} \mathrm{H}\right]$ cyanophycin equivalent to $80 \mu \mathrm{g}$ arginine, in a total volume of $500 \mu \mathrm{l}$. At 0,20 and $40 \mathrm{~min}, 100 \mu \mathrm{l} \mathrm{samples} \mathrm{were} \mathrm{removed} \mathrm{from} \mathrm{the} \mathrm{incubation} \mathrm{mixtures} \mathrm{and}$ treated with $25 \mu \mathrm{l} 25 \%(\mathrm{w} / \mathrm{v})$ trichloroacetic acid. [ $\left.{ }^{3} \mathrm{H}\right]$ Arginine released into the TCA-supernatant was detected by scintillation counting.

\section{Results}

Transient cyanophycin accumulation in nickel-replete cells

In the experiments reported previously with nickeldepleted cells (Daday et al., 1988), the presence of $0.18 \mathrm{~mm}$-ammonia $\left(\mathrm{NH}_{3}+\mathrm{NH}_{4}^{+}\right)$would have supported growth to approximately 10 Klett units. A higher initial concentration of ammonia would allow the transition to the nitrogen-fixing state to occur at a higher cell density and would thus facilitate the investigation of cyanophycin accumulation and degradation. An initial concentration of $0.8 \mathrm{mM}$-ammonia was routinely used for the experiments reported in this paper.

Nickel-deficient $A$. cylindrica with repressed nitrogenase (produced by growth in the presence of $4 \mathrm{mM}$ ammonia) was inoculated into medium containing $0.8 \mathrm{mM}$-ammonia in the presence and absence of $0.68 \mu \mathrm{M}-\mathrm{NiSO}_{4}$. A transient accumulation of cyano- 


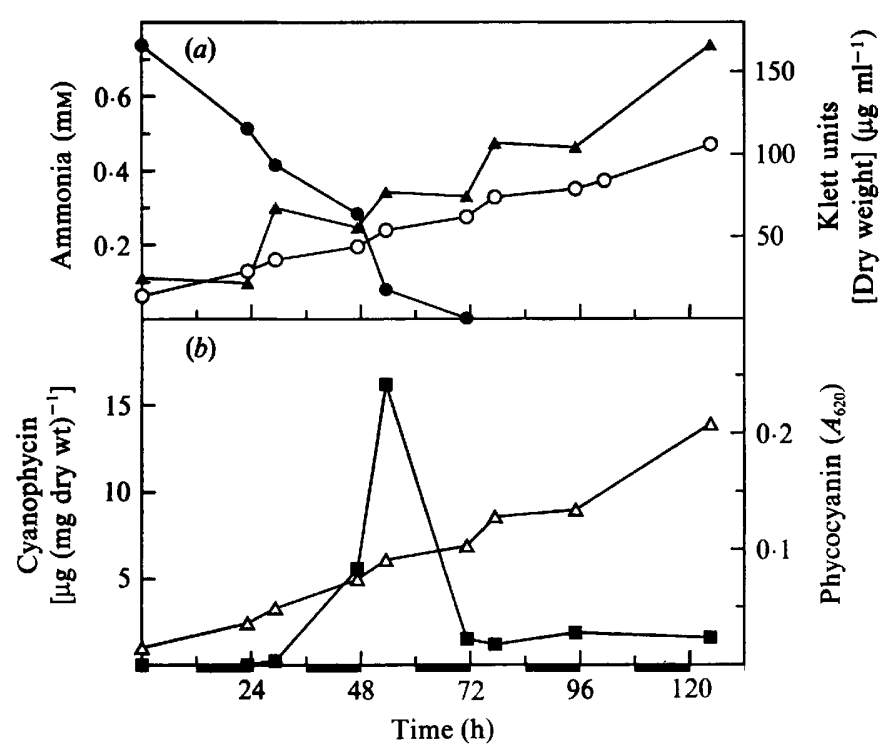

Fig. 1. Cyanophycin synthesis and degradation in $A$. cylindrica. Nickel-depleted $A$. cylindrica, grown in the presence of $4 \mathrm{~mm}-$ $\mathrm{NH}_{4} \mathrm{H}_{2} \mathrm{PO}_{4}$ (Specpure), was used to inoculate two cultures to an initial concentration of 2 Klett units. $\mathrm{NH}_{4} \mathrm{H}_{2} \mathrm{PO}_{4}$ was added to an initial concentration of $0.8 \mathrm{~mm}$. One culture was maintained in nickeldepleted conditions (not shown), the other had $0.68 \mu \mathrm{M}-\mathrm{NiSO}_{4}$ added. The first measurements $(t=0)$ of cell density $(O)$, dry weight $(\Delta)$, phycocyanin $(\Delta)$, cyanophycin $(\square)$ and ammonia remaining in the medium (๑) were made $3 \mathrm{~d}$ after inoculation. The dark bars on the $x$-axes of this and the following figures indicate periods of darkness.

phycin was observed in nickel-sufficient cells as the ammonia was consumed (Fig. 1); an identical result was obtained with nickel-depleted cells (result not shown). Clearly the absence of nickel per se does not cause the synthesis and degradation of cyanophycin seen here. In the light of this result, the remaining experiments reported in this paper were done in the presence of $0.68 \mu \mathrm{M}-\mathrm{NiSO}_{4}$.

\section{Abrupt and gradual nitrogen starvation}

It can be seen from Fig. 1 that cyanophycin was synthesized and degraded during a period of gradual depletion of extracellular ammonia, which might be a signal of impending nitrogen shortage (Parnas \& Cohen, 1976). To test whether cyanophycin was synthesized as a response to that signal, experiments were done to determine whether cyanophycin synthesis occurred when $A$. cylindrica was abruptly deprived of fixed nitrogen.

Two cultures were inoculated with ammonia-grown A. cylindrica. The control culture had an initial concentration of $0.8 \mathrm{~mm}$-ammonia. The ammonia was gradually used, and cyanophycin accumulated transiently in a similar way to that described by Fig. 1. The second culture had no added nitrogen and these cells thus experienced abrupt nitrogen starvation. No cyanophycin accumulation was seen and any cyanophycin present in the inoculum was rapidly degraded (result not shown). Nitrogenase activity was induced within $24 \mathrm{~h}$ in the abruptly starved culture but did not appear in the culture with $0.8 \mathrm{~mm}$-ammonia until all the ammonia had been removed from the medium.

\section{Gradual nitrogen starvation followed by repletion in Synechocystis 6308 and A. cylindrica}

The complete consumption of extracellular ammonia signals the need for differentiation of heterocysts and synthesis of nitrogenase in $A$. cylindrica. Provided $\mathrm{N}_{2}$ is available, any period of nitrogen limitation will be temporary, so the reasons for cyanophycin synthesis during the transition from ammonia consumption to nitrogen fixation in $A$. cylindrica are not obvious. However, in organisms such as Synechocystis 6308 which do not fix nitrogen, the exhaustion of extracellular ammonia signals the beginning of an indefinite period of nitrogen starvation. An experiment was done to determine whether transient accumulations of cyanophycin also occurred in cells of Synechocystis 6308 which were allowed to consume a limited amount of ammonia. Once they become nitrogen-starved, such cells are analogous to those used by Allen \& Hutchison (1980), who investigated cyanophycin metabolism following the addition of nitrogen to nitrogen-starved cells. Consequently the experiment was continued to investigate this second set of conditions.

Synechocystis, which had been grown in either ammonia or urea, was used to inoculate medium containing $0.8 \mathrm{~mm}$-ammonia. The ammonia was consumed within $3 \mathrm{~d}$ of growth, at which time the cells became nitrogen starved. Four days later, $\left(\mathrm{NH}_{4}\right)_{2} \mathrm{HPO}_{4}$ was added to the culture to give a concentration of $3 \mathrm{mM}$-ammonia, and visual observations and measurements were continued (Fig. 2). Cyanophycin accumulated transiently in Synechocystis before the initial amount of ammonia was completely consumed. After exhaustion of the ammonia, nitrogen starvation was indicated by yellowing of the cells and was confirmed both by the drop in $A_{620}$ (Fig. $2 c$ ) and a cessation of net protein synthesis (Fig. $2 b$ ). Cell density (Klett units) and dry weight continued to increase, indicating carbohydrate accumulation (cf. Lehmann \& Wober, 1976; Allen \& Smith, 1969). When ammonia was added back to the cells, a second peak of cyanophycin was observed (Fig. 2c). The cyanophycin was synthesized and degraded on a similar timescale to that observed by Allen \& Hutchison (1980). It can be seen that cyanophycin 


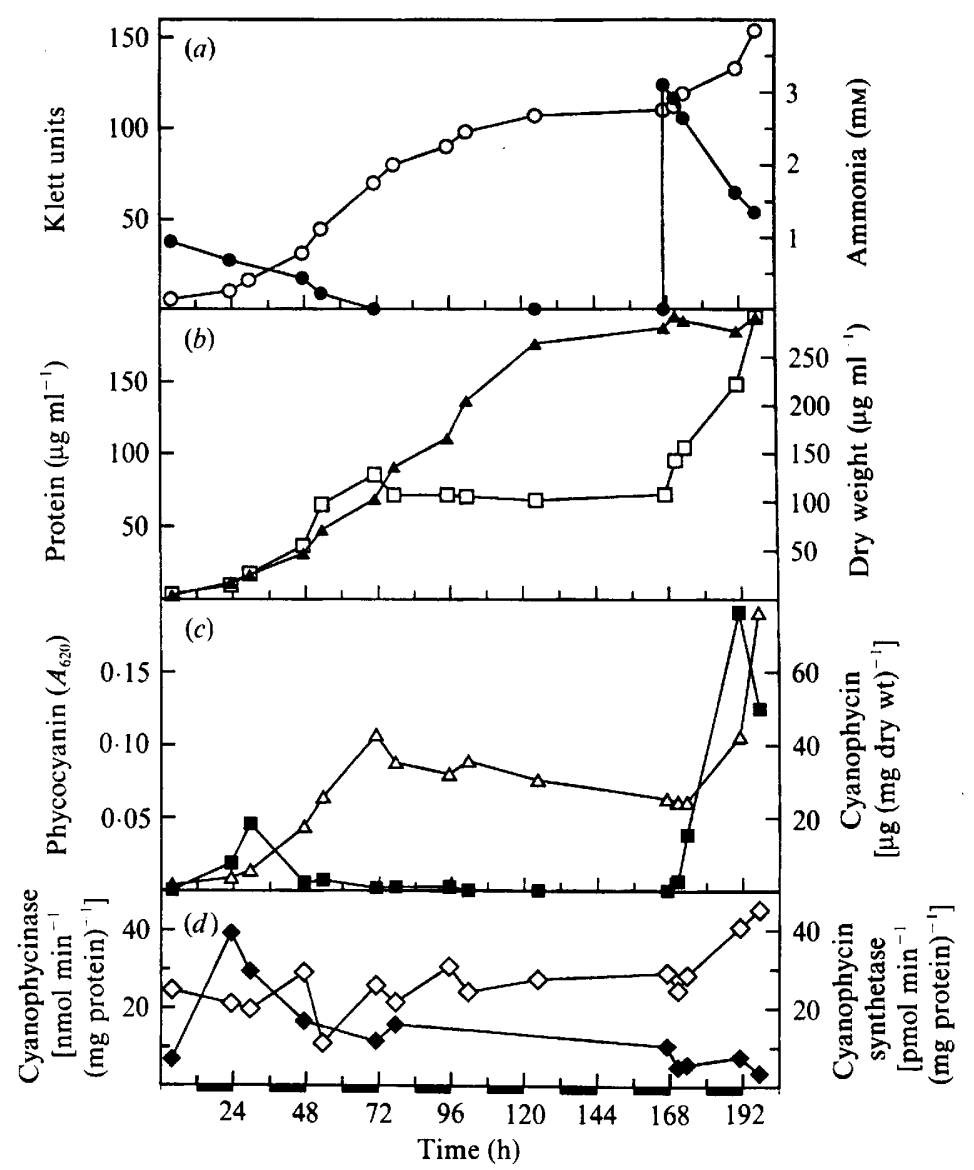

Fig. 2. Nitrogen starvation, followed by repletion, in Synechocystis 6308. A 101 culture was inoculated with urea-grown Synechocystis, to give an initial concentration of $2 \mathrm{Klett}$ units. The initial ammonia concentration was $0.8 \mathrm{mM}$, which was exhausted after $72 \mathrm{~h}$ growth. After $96 \mathrm{~h}$ of nitrogen starvation, $\left(\mathrm{NH}_{4}\right)_{2} \mathrm{HPO}_{4}$ was added $(a t=168 \mathrm{~h})$ to give an ammonia concentration of approximately $3 \mathrm{~mm}$. (a) Cell density $(O)$, and $\mathrm{NH}_{3}$ concentration $(\bullet)$. (b) Protein $(\square)$ and dry weight $(\boldsymbol{\Delta})$. (c) Phycocyanin $(\Delta)$ and cyanophycin $(\boldsymbol{\square})$. (d) Cyanophycinase $(\diamond)$ and cyanophycin synthetase $(\bullet)$ activities.

synthesis commenced immediately following addition of ammonia.

The analogous experiment was then done with A. cylindrica (Fig. 3). Urea-grown $A$. cylindrica was used to inoculate medium containing $0.8 \mathrm{~mm}$-ammonia. The cells were then incubated under an atmosphere of $\mathrm{Ar} / \mathrm{O}_{2} / \mathrm{CO}_{2}(79 \cdot 7: 20: 0 \cdot 3$, by vol.) so that they became nitrogen-starved following depletion of the initial ammonia. As seen previously, a peak of cyanophycin was observed while the initial ammonia was consumed (Fig. $3 c$ ). The culture then became nitrogen-starved. After $3 \mathrm{~d}$ of nitrogen starvation, $\left(\mathrm{NH}_{4}\right)_{2} \mathrm{HPO}_{4}$ was added to give a concentration of $2.8 \mathrm{~mm}$-ammonia and a transient accumulation of cyanophycin was observed (Fig. 3c). In contrast, when nitrogen recovery was induced by changing the cells back to nitrogen-fixing conditions (gassing with $0.3 \% \mathrm{CO}_{2}$ in air), only a very small cyanophycin peak [0.14 $\mu \mathrm{g}$ cyanophycin (mg dry weight) ${ }^{-1}$ ] was found (result not shown).

\section{Effect of constant ammonia supply following nitrogen repletion}

The addition of a nitrogen source to nitrogen-starved cells exposed them to a sudden increase in usable nitrogen followed by a period of gradually declining concentration. It was not clear whether cyanophycin accumulation under these conditions was triggered by the initial sudden increase or the subsequent gradual decline in the availability of fixed nitrogen (Figs 2 and 3). In an attempt to distinguish between these possibilities, an experiment was set up where fixed nitrogen was replenished and its concentration was then kept essentially constant. A culture of Synechocystis was allowed to become nitrogen-starved as described in Fig. 2, ammonia was added to give a concentration of $4 \mathrm{~mm}$, and that level was maintained as precisely as possible for $3 \mathrm{~d}$ by repeated addition of ammonia. The ammonia concentration was maintained between $4.85 \mathrm{mM}$ and 


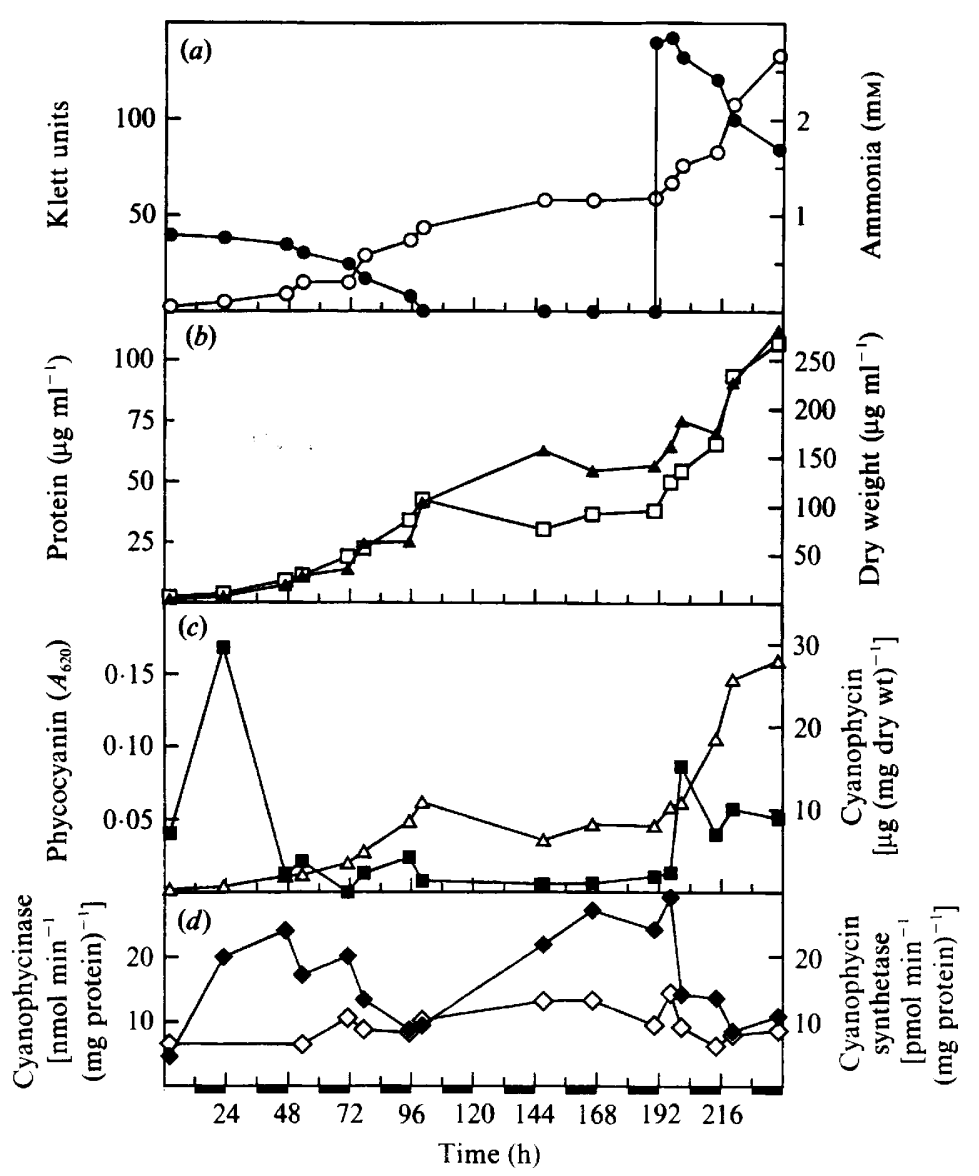

Fig. 3. Nitrogen starvation, followed by repletion, in $A$. cylindrica. Urea-grown $A$. cylindrica was used to inoculate a culture under the same initial conditions as described for Fig. 2. The culture was sparged with $\mathrm{Ar} / \mathrm{O}_{2} / \mathrm{CO}_{2}(79 \cdot 7: 20: 0 \cdot 3$, by vol.) and cells were sampled with a siphon which allowed the gas headspace to remain undisturbed throughout the experiment. Ammonia was exhausted after $100 \mathrm{~h}$, and the cells remained nitrogen-deficient for $90 \mathrm{~h} .\left(\mathrm{NH}_{4}\right)_{2} \mathrm{HPO}_{4}$ was then added to give an ammonia concentration of approximately $3 \mathrm{~mm}$. Symbols as in Fig. 2.

$3 \cdot 18 \mathrm{mM}$ during this period, in contrast to the situation in the earlier experiment (Fig. 2), in which the ammonia concentration dropped steadily from $3 \mathrm{mM}$ to $1.35 \mathrm{~mm}$. The results of the experiment are shown in Fig. 4. Cyanophycin synthesis again commenced immediately following the addition of ammonia, and degradation was complete $30 \mathrm{~h}$ later.

The nature of cyanophycin accumulation in nitrogenreplete $A$. cylindrica

Lawry \& Simon (1982) reported that cyanophycin was detectable $48 \mathrm{~h}$ after the addition of a source of fixed nitrogen to $\mathrm{N}_{2}$-fixing $A$. cylindrica. To determine whether cyanophycin was synthesized and then degraded under these conditions, we investigated cyanophycin levels at intervals following the addition of ammonia to $\mathrm{N}_{2}$-fixing $A$. cylindrica. Cyanophycin synthesis commenced within $6 \mathrm{~h}$ of ammonia addition (result not shown). The accumulation was again transient; cyanophycin levels had declined to initial values $48 \mathrm{~h}$ after ammonia addition. The peak level of cyanophycin corresponded to approximately $0.7 \%$ of dry weight.

\section{Activity of cyanophycin synthetase and cyanophycinase}

The activity of cyanophycin synthetase and cyanophycinase during nitrogen starvation and nitrogen repletion is shown in Figs $2(d)$ and $3(d)$. It is apparent that both activities are constitutive in $A$. cylindrica and Synechocystis 6308. To our knowledge this is the first report of the direct measurement of cyanophycin synthetase activity in Synechocystis; its presence had previously been inferred but not measured (Allen \& Hutchison, 1980).

The data presented in Figs 2 and 3 raise questions about how these enzyme activities are regulated in vivo. 


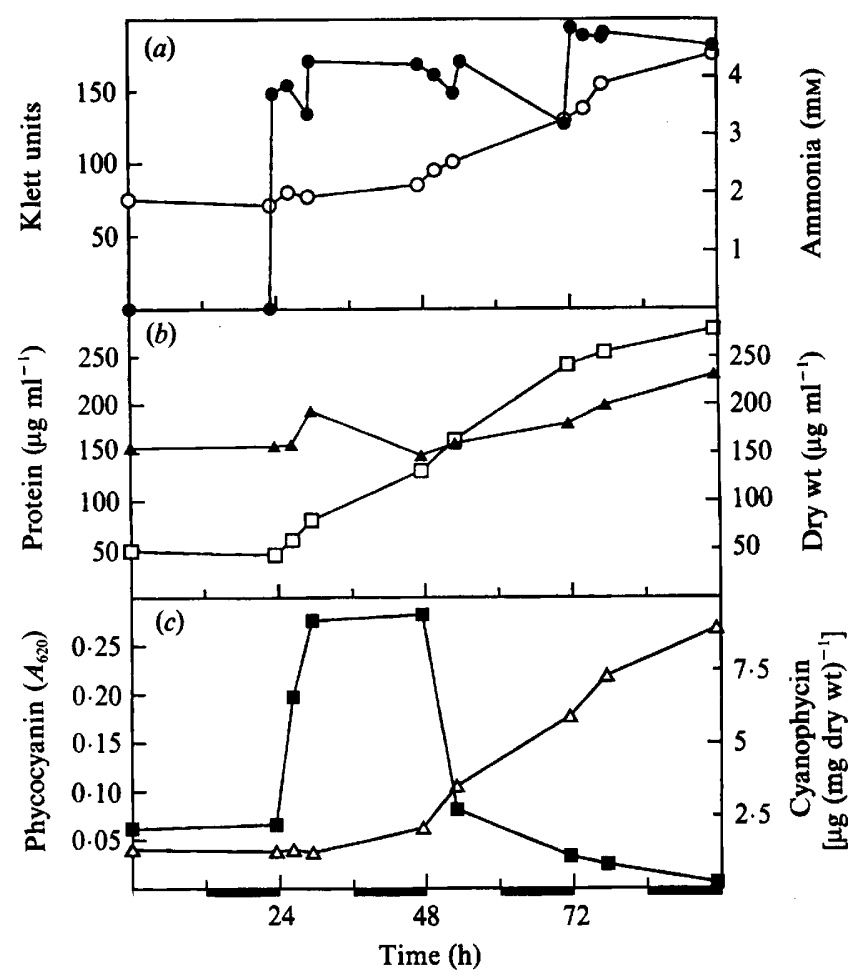

Fig. 4. Cyanophycin synthesis and degradation following ammonia addition, and during a subsequent period of constant ammonia concentration. Ammonia-grown Synechocystis was inoculated into medium containing $0.4 \mathrm{~mm}$-ammonia. The cells consumed the ammonia, and were then allowed to become visibly nitrogen-starved. $\left(\mathrm{NH}_{4}\right)_{2} \mathrm{HPO}_{4}(\theta)$ was added $(t=24 \mathrm{~h})$ to give an ammonia concentration of $4 \mathrm{~mm}$, and the ammonia concentration was monitored periodically during the following $3 \mathrm{~d}$. More ammonia was added as necessary to maintain the concentration as close to $4 \mathrm{mM}$ as possible. Cell density $(O)$, protein $(\square)$, dry weight $(\Delta)$, phycocyanin $(\triangle)$, and cyanophycin ( $\square$ ) were estimated.

Presumably there are mechanisms for regulation through low molecular mass effectors, since periods of net synthesis and net degradation occur although both activities are present.

\section{Discussion}

Cyanophycin clearly has a dynamic metabolism, in that it can accumulate in a transient manner which is apparently unrelated to its accumulation as a reserve compound during the transition from exponential growth to stationary phase. Although it has been reported previously that a transient accumulation of cyanophycin in A. cylindrica is related to a condition of nickel depletion (Daday et al., 1988), further work has shown that, in fact, the transient accumulation is also observed in nickel-replete cells, but that its timing can be affected by the presence or absence of nickel. Nickel can influence the extent of the growth lag associated with a transition to the nitrogen-fixing metabolic state. This growth lag is sensitive to very low concentrations of nickel, and could be abolished by concentrations which produced urease activity as low as $7 \%$ of maximum (results not shown). Routine inclusion of nickel in the culture medium allowed the transient cyanophycin accumulation to be studied independently of the growth lag.

The results presented in this paper confirm that there are two distinct sets of conditions where transient accumulations of cyanophycin are observed. First, when cells were inoculated into fresh medium containing a limited amount of ammonia, cyanophycin was transiently observed before extracellular ammonia was completely depleted. Accumulation of cyanophycin under these conditions has not previously been reported and we suggest that this represents a new aspect of cyanophycin metabolism. Secondly, cyanophycin was synthesized immediately following the addition of a usable source of fixed nitrogen to nitrogen-starved cells. In this discussion, these transient accumulations of cyanophycin will be referred to as the first and second cyanophycin peaks, respectively. Both peaks were observed in A. cylindrica and Synechocystis 6308.

The first peak occurred while fixed nitrogen was being removed from the medium to support cell growth (Figs 1, 2 and 3). The cells thus appeared to sense a declining concentration of extracellular nitrogen. According to Parnas \& Cohen (1976), this situation would signal that a period of nitrogen starvation was imminent and would trigger the synthesis of cyanophycin to support the cells through the period of deficiency. The timing of cyanophycin synthesis fitted this pattern; cyanophycin synthesis usually commenced when the ammonia concentration had reached a low level but before it was completely exhausted (Figs 1, 2 and 3). By synthesizing cyanophycin at this time, cyanobacteria could maximize their share of available nitrogen without having to alter the rates of synthesis of other cell components; increasing the rate of protein synthesis would require adjustments to ribosome numbers and other synthetic machinery (Koch, 1988) and merely increasing intracellular concentrations of ammonia, glutamine or other amino acids might have inhibitory effects on enzyme activities (Simon, 1987; Carr, 1988). Thus, synthesis of cyanophycin could give cyanobacteria a competitive advantage at little cost to the cells. The results obtained when $A$. cylindrica was abruptly deprived of ammonia also support the above observations; such cells did not experience a period of gradual depletion and no cyanophycin was synthesized. Any cyanophycin present in the cells at the time of inoculation was rapidly 
degraded, in agreement with the findings of others who have noted the rapid degradation of cyanophycin in response to abrupt nitrogen deprivation (e.g. Allen, 1984).

At first sight the rapid degradation of cyanophycin is not so easily explained. If the function of cyanophycin is to supply controlled amounts of nitrogen for maintenance and growth of cells during periods of nitrogen starvation, then cyanophycin levels would be expected to decline gradually during the period of nitrogen starvation. Instead, degradation of cyanophycin was usually complete by the time extracellular ammonia became undetectable. However, once the external supply of nitrogen is exhausted, the cell has to deploy a finite amount of nitrogen to the best advantage. Unlike phycocyanin, cyanophycin has no functional activity in the cell. Therefore, leaving nitrogen sequestered as cyanophycin at this time would not make the best use of that nitrogen. Degradation of cyanophycin would allow the cells to distribute a limited, but constant, amount of nitrogen into proteins which maximized the cells' ability to survive a period of nitrogen starvation. An alternative view is that the cyanophycin accumulation functions in some way as a signal indicating metabolic change. The mechanism of this signal is clearly unknown although it might relate to a channelling of nitrogen into amino acids and other chemicals which form during cyanophycin degradation.

The results illustrate a subtle difference between the regulation of energy storage compounds such as glycogen, and other nutrient stores such as cyanophycin. In energy-limited cells, an energy store must be used at a controlled rate throughout the period of starvation, since survival depends on rationing the store so that it lasts (Cohen \& Parnas, 1976; Parnas \& Cohen, 1976; Mur, 1983). Once the energy store has been used it cannot be recovered. This contrasts with the situation during starvation for other nutrients. Here the total amount of nutrient remains constant but its distribution among subcellular pools can be changed as necessary. The nutrient is not being irretrievably lost from the cell.

The second type of cyanophycin peak occurred when nitrogen-starved $A$. cylindrica or Synechocystis cells were given a usable source of fixed nitrogen (Figs 2 and 3 ). This phenomenon had previously been noted qualitatively in A. cylindrica (de Vasconcelos \& Fay, 1974) and studied quantitatively in Synechocystis 6308 (Allen \& Hutchison, 1980). It appears to be a response to the suddenly renewed availability of fixed nitrogen rather than to the declining concentration of extracellular nitrogen (cf. Fig. 2 and Fig. 4).

Prolonged nitrogen starvation of cyanobacterial cells involves the degradation of phycobilisomes, followed by degradation of either thylakoid membranes or ribo- somes, or both (de Vasconcelos \& Fay, 1974; Stevens et al., 1981 a; Wanner et al., 1986). Glycogen accumulates during the period of nitrogen starvation. The addition of nitrogen to starved cells causes the degradation of glycogen and the resynthesis of cell components before growth recommences (e.g. see Allen \& Smith, 1969; Lehmann \& Wober, 1976). Typical features of nitrogen starvation were observed in the experiments described here: accumulation of protein and phycocyanin ceased, then phycocyanin was degraded, while dry weight and cell density continued to increase, implying the accumulation of glycogen. (Glycogen levels were not measured directly in these experiments because of lack of cell material.) It could be noted that the amounts of cyanophycin synthesized during recovery from nitrogen starvation varied in different experiments. This presumably relates to the length of the prior period of nitrogen starvation, which would affect both the amount of glycogen stored and the extent of degradation of the cellular components listed above; these factors would determine the availability of carbon skeletons, and possibly the relative amount of nitrogen incorporated into cyanophycin as opposed to other nitrogenous molecules.

Following addition of nitrogen to the starved cells, there was a slight lag before protein and phycocyanin synthesis commenced, and a longer lag before dry weight started to increase. These results agree closely with those reported by Allen \& Hutchison (1980). During the lag period, glycogen would have been broken down and thylakoid membranes, ribosomes and phycobilisomes resynthesized. The degradation of glycogen would lead to the release of carbon compounds which could act as carbon skeletons for cyanophycin synthesis. Evidence that this may occur comes from Allen \& Hutchison (1980), who noted that little ${ }^{14} \mathrm{C}$-label from extracellular arginine or glutamine appeared in cyanophycin during its synthesis under these conditions. On the other hand, nitrogen from the supplied organic nitrogen source would be used to synthesize glutamate and then cyanophycin. This contrasts with previous evidence that cyanophycin is synthesized from products of protein degradation (Simon, 1973; Allen et al., 1980; Allen \& Hawley, 1983; Stevens et al., 1981 b).

Synthesis of cyanophycin in response to addition of a nitrogen source to nitrogen-starved cells would allow the cells to maximize their accumulation of nitrogen as it became available. Direct channelling of nitrogen into protein during the recovery period would not accumulate nitrogen as rapidly, since the full complement of ribosomes would not yet have been replaced (Allen \& Hutchison, 1980; Allen \& Smith, 1969). Many of the enzymes involved in nitrogen assimilation (e.g. nitrate reductase, glutamine synthetase, phosphoenolpyruvate 
carboxylase, glutamate-oxaloacetate transaminase) are enhanced in nitrogen-starved conditions but repressed by growth on ammonia (Flores et al., 1983; Meeks et al., 1977; Rowell et al., 1977; Rowell \& Stewart, 1976). Therefore, it would be an advantage for cells to be able to minimize intracellular ammonia concentrations, or concentrations of other compounds which signal the need to repress these enzymes, while maximizing their assimilation of available nitrogen during recovery from nitrogen starvation. The use of carbon skeletons from glycogen to synthesize cyanophycin would do this very well.

Once ribosomes, phycobilisomes and thylakoid membranes have been resynthesized, cells would again be capable of balanced growth. The timing of cyanophycin degradation would suggest that when this resynthesis of cell components is achieved, cyanophycin can be degraded, because the nitrogen assimilation capacity and protein synthesis rate are again balanced (cf. Allen $e t$ al., 1980). The aspartate and arginine released would presumably then be incorporated into cell protein, either unchanged or following transamination and further metabolism.

There are two possible reasons for the failure of $A$. cylindrica to synthesize cyanophycin when resupplied with $\mathrm{N}_{2}$ rather than ammonia. Synthesis of cyanophycin appears to be a response to changes in availability of fixed nitrogen. Nitrogen gas is likely to be present in all micro-environments inhabited by cyanobacteria, although its concentration could vary. The complete absence of $\mathrm{N}_{2}$ obtained experimentally is thus unphysiological and cyanobacteria may not have the mechanisms to respond to its absence and resupply. Alternatively, nitrogenase may not produce ammonia quickly enough for the cells to be aware of a sudden influx of fixed nitrogen. This result is analogous to those in the accompanying paper, obtained with nitrogen-fixing A. cylindrica grown on light/dark cycles, where although nitrogen fixation, and hence supply of fixed nitrogen, ceased during the dark period, there was no evidence of cyanophycin synthesis when nitrogen fixation recommenced in the light (Mackerras et al., 1990).

The synthesis of cyanophycin when ammonia was added to nitrogen-fixing $\boldsymbol{A}$. cylindrica is probably a similar phenomenon to that observed when fixed nitrogen was added to nitrogen-deficient cells. That is, vegetative cells maximize their share of any available nitrogen by synthesizing cyanophycin. However, the amounts of cyanophycin synthesized were smaller. This could be due to the lower availability of carbon skeletons. Nitrogen-replete cells would not be expected to have the same reserves of carbohydrate as nitrogen-deficient cells. The peak amount of cyanophycin seen was less than that reported by Lawry \& Simon (1982) but they used a microscopic method for estimating cyanophycin which does not correlate exactly with chemical methods. In addition, subtle variations in growth conditions can lead to profound variations in cyanophycin metabolism.

The second cyanophycin peak is reminiscent of the 'polyphosphate overplus' phenomenon noted previously (Grillo \& Gibson, 1979; Simon, 1987) in that the reserve compound accumulated rapidly and transiently when repletion followed a period of nutrient starvation. However unlike polyphosphate, cyanophycin synthesis is unlikely to be a response to increased rates of uptake of nitrogen sources, since there is little evidence that these are enhanced in cyanobacteria by periods of nitrogen starvation (e.g. Boussiba et al., 1984). Similar results were obtained with ammonia, nitrate, urea and arginine in Synechocystis 6308 (Allen \& Hutchison, 1980) and there is no evidence that the uptake processes for all of these compounds are derepressed in response to nitrogen deprivation. In addition, there was no evidence that enhanced activity of cyanophycin synthetase occurred in response to nitrogen starvation (Figs 2 and 3). The mechanisms controlling this transient synthesis of cyanophycin are still obscure. However, as stated above, the enzyme activities must be regulated in some manner because periods of net accumulation and net degradation (Figs 2 and 3) occurred when both activities were detectable.

In conclusion, the present work confirms earlier suggestions that cyanophycin, rather than simply functioning as a relatively inert reserve compound in the stationary phase of growth, has a dynamic metabolism in response to the changing nitrogen status of cyanobacterial cells. Under these conditions, cyanophycin serves as a reservoir of nitrogen, separating environmental supply from the metabolic demands of the organism, but it appears that Carr's hypothesis (Carr, 1983) that cyanophycin serves only as a reservoir between nitrogen fixation and biosynthesis is too limited. A more comprehensive statement of the situation is that cyanophycin serves as a reservoir of newly assimilated nitrogen, which allows maximal acquisition of fixed nitrogen over relatively short time periods, and subsequent use of that nitrogen for growth or survival. Both of the cyanophycin peaks discussed in this paper fit this hypothesis, since they occur in situations where such 'forward planning' would give cyanobacteria a competitive advantage over other organisms.

\section{References}

Allen, M. B. \& ARNoN, D. I. (1955). Studies on nitrogen-fixing bluegreen algae. I. Growth and nitrogen fixation by Anabaena cylindrica Lemm. Plant Physiology 30, 366-372.

ALLEN, M. M. (1968). Simple conditions for the growth of unicellular blue-green algae on plates. Journal of Phycology 4, 1-4. 
Allen, M. M. (1984). Cyanobacterial cell inclusions. Annual Review of Microbiology 38, 1-25.

Allen, M. M. \& Hawley, M. A. (1983). Protein degradation and synthesis of cyanophycin granule polypeptide in Aphanocapsa sp. Journal of Bacteriology 154, 1480-1484.

Allen, M. M. \& Hutchison, F. (1980). Nitrogen limitation and recovery in the cyanobacterium Aphanocapsa 6308. Archives of Microbiology 128, 1-7.

Allen, M. M. \& SMrth, A. J. (1969). Nitrogen chlorosis in blue-green algae. Archives of Microbiology 69, 114-120.

Allen, M. M., Hutchison, F. \& Weathers, P. J. (1980). Cyanophycin granule polypeptide formation and degradation in the cyanobacterium Aphanocapsa 6308. Journal of Bacteriology 141, 687-693.

BERGERSEN, F. J. (1980). Measurement of nitrogen fixation by direct means. In Methods for Evaluating Biological Nitrogen Fixation, pp. 66-110. Edited by F. J. Bergersen. Chichester: John Wiley.

Boussiba, S., Resch, C. M. \& Gibson, J. (1984). Ammonia uptake and retention in some cyanobacteria. Archives of Microbiology 138, 287-292.

CARR, N. G. (1983). Biochemical aspects of heterocyst differentiation and function. In Photosynthetic Prokaryotes: Cell Differentiation and Function, pp. 265-280. Edited by G. C. Papageorgiou \& L. Packer. New York \& Amsterdam: Elsevier.

CARR, N. G. (1988). Nitrogen reserves and dynamic reservoirs in cyanobacteria. In Biochemistry of the Algae and Cyanobacteria (Annual Proceedings of the Phytochemical Society of Europe), pp. 13-21. Edited by L. J. Rogers and J. R. Gallon. Oxford: Clarendon Press.

COHEN, D. \& Parnas, H. (1976). An optimal policy for the metabolism of storage materials in unicellular algae. Journal of Theoretical Biology 56, 1-18.

Daday, A., MackerRas, A. H. \& SMith, G. D. (1988). A role for nickel in cyanobacterial nitrogen fixation and growth via cyanophycin metabolism. Journal of General Microbiology 134, 2659-2663.

DAWES, E. A. \& SENIOR, P. J. (1973). The role and regulation of energy reserve polymers in micro-organisms. Advances in Microbial Physiology 10, 135-266.

Flores, E., Ramos, J. L., Herrero, A. \& Guerrero, M. G. (1983). Nitrate assimilation by cyanobacteria. In Photosynthetic Prokaryotes: Cell Differentiation and Function, pp. 363-387. Edited by G. C. Papageorgiou \& L. Packer. New York \& Amsterdam: Elsevier.

GuPTA, M. \& CARR, N. G. (1981). Enzyme activities related to cyanophycin metabolism in heterocysts and vegetative cells of Anabaena spp. Journal of General Microbiology 125, 17-23.

Grillo, J. F. \& 'GIBson, J. (1979). Regulation of phosphate accumulation in the unicellular cyanobacterium Synechococcus. Journal of Bacteriology 140, 508-517.

Koch, A. L. (1988). Why can't a cell grow infinitely fast? Canadian Journal of Microbiology 34, 421-426.

LAWRY, N. H. \& SIMON, R. D. (1982). The normal and induced occurrence of cyanophycin inclusion bodies in several blue-green algae. Journal of Phycology 18, 391-399.
LehmanN, M. \& WoBer, G. (1976). Accumulation, mobilization and turn-over of glycogen in the blue-green bacterium Anacystis nidulans. Archives of Microbiology 111, 93-97.

MaCkerRas, A. H., Youens, B. N., WeIR, R. C. \& SMITH, G. D. (1990). Is cyanophycin involved in the integration of nitrogen and carbon metabolism in the cyanobacteria Anabaena cylindrica and Gloeothece grown on light/dark cycles? Journal of General Microbiology 136, 2049-2056.

Meeks, J. C., Wolk, C. P., Thomas, J., Lockau, W., Shaffer, P. W. Austin, S. M., ChIEN, W.-S. \& Galonsky, A. (1977). The pathways of assimilation of ${ }^{13} \mathrm{NH}_{4}^{+}$by the cyanobacterium, Anabaena cylindrica. Journal of Biological Chemistry 252, 7894-7900.

MUR, L. R. (1983). Some aspects of the ecophysiology of cyanobacteria. Annales de Microbiologie 134B, 61-72.

Parnas, H. \& Cohen, D. (1976). The optimal strategy for the metabolism of reserve materials in micro-organisms. Journal of Theoretical Biology 56, 19-55.

Rowell, P. \& SteWART, W. D. P. (1976). Alanine dehydrogenase of the $\mathrm{N}_{2}$-fixing blue-green alga, Anabaena cylindrica. Archives of Microbiology 107, 115-124.

Rowell, P., ENTICotT, S. \& StewarT, W. D. P. (1977). Glutamine synthetase and nitrogenase activity in the blue-green alga Anabaena cylindrica. New Phytologist 79, 41-54.

SChWINGHAmer, E. A. (1980). A method for improved lysis of some gram-negative bacteria. FEMS Microbiology Letters 7, 157-162.

SimON, R. D. (1973). Measurement of the cyanophycin granule polypeptide contained in the blue-green alga Anabaena cylindrica. Journal of Bacteriology 114, 1213-1216.

SIMON, R. D. (1976). The biosynthesis of multi-L-arginyl-poly(L-aspartic acid) in the filamentous cyanobacterium Anabaena cylindrica. Biochimica et Biophysica Acta 422, 407-418.

SimoN, R. D. (1987). Inclusion bodies in the cyanobacteria: cyanophycin, polyphosphate, polyhedral bodies. In The Cyanobacteria, pp. 199-225. Edited by P. Fay \& C. Van Baalen. Amsterdam \& New York: Elsevier.

Stevens, S. E., Balkwill, D. L. \& PaOne, D. A. M. (1981a). The effects of nitrogen limitation on the ultrastructure of the cyanobacterium Agmenellum quadruplicatum. Archives of Microbiology 130 , 204-212.

Stevens, S. E., Paone, D. A. M. \& Balxwill, D. L. (1981b). Accumulation of cyanophycin granules as a result of phosphate limitation in Agmenellum quadruplicatum. Plant Physiology 67, 716-719.

DE Vasconcelos, L. \& FAY, P. (1974). Nitrogen metabolism and ultrastructure in Anabaena cylindrica. I. The effect of nitrogen starvation. Archives of Microbiology 96, 271-279.

WanNer, G., HenkelmanN, G., SChimid, A. \& Kost, H.-P. (1986). Nitrogen and sulfur starvation of cyanobacterium Synechococcus 6301. An ultrastructural, morphometrical and biochemical comparison. Zeitschrift für Naturforschung 41c, 741-750. 